\title{
"Uma ponte para o futuro": efeitos de sentido do discurso neoliberal no Brasil
}

\author{
João Francisco TENÓRIO NETO ৫ \\ Universidade Federal de Alagoas (UFAL) \\ Sóstenes ERICSON 『 \\ Universidade Federal de Alagoas (UFAL)
}

\section{ఠ}

OPEN ACCESS

EDITADO POR

- Evandra Grigoletto (UFPE)

- Bethania Mariani (UFF)

- Gian Luigi De Rosa (UNIROMA)

AVALIADO POR

- Lauro Baldini (UNICAMP)

- Andrea Rodrigues (UERJ)

SOBRE OS AUTORES

- João Francisco Tenório Neto

Escrita - rascunho original -,

Escrita - análise e edição.

- Sóstenes Ericson

Escrita - rascunho original -,

Escrita - análise e edição.

\section{DATAS}

- Recebido: 28/10/2020

- Aceito: 23/11/2020

- Publicado: 17/12/2020

\section{RESUMO}

Com base na análise materialista do discurso (PÊCHEUX, 2015; 2014), este artigo tem por objetivo ressaltar a opacidade da linguagem, a partir dos efeitos de sentido do discurso neoliberal, no cenário brasileiro do golpe de 2016, analisando um corpus extraído do documento "Uma ponte para o Futuro" (PMDB, 2015). Considerando os domínios de antecipação, atualidade e memória (COURTINE, 2014), demonstra-se como o discurso neoliberal se apresenta, silenciando o antagonismo de classes sociais, enquanto recupera uma memória que historicamente funciona para reforçar uma unidade nacional em prol de um futuro que não chega. No intradiscurso, o efeito de atualidade materializa no presente a necessidade de romper com um passado, associado aos governos petistas, apresentando uma proposta de governo alinhada aos interesses dominantes, metaforizada numa ponte que conduzirá o país ao desenvolvimento. O que se tem em conta, por antecipação, é a tentativa de identificação da classe trabalhadora com as necessidades apontadas como sendo do conjunto da sociedade brasileira, representada pela burguesia, e a defesa dos interesses políticos e econômicos do Estado nacional, nos moldes do modelo neoliberal. Para quem ousa se revoltar, desconstruir esta ponte é o desafio histórico que está posto no tempo presente.

\section{ABSTRACT}

Based on the materalistic analysis of the discourse (PÊCHEUX, 2015; 2014), this article aims to stand out the opacity of language, based on the sense 


\section{REVISTA DA ABRALIN}

effects of neoliberal discourse, in the Brazilian scenario of the 2016 coup, analyzing a corpus extracted from the document "A bridge to the future" (PMDB, 2015). Considering the domains of anticipation, actuality and memory (COURTINE, 2014), it demonstrates how the neoliberal discourse presentes itself, silencing the antagonism of social classes, while recovering a memory that historically works to reinforce a national unity in favor of a future that not enough. In the intradiscourse, the effect of actuality materializes in the present the need to break with the past, associated with PT governments, presenting a government proposal aligned with dominant interests, metaphorized on a brigde that will lead the country to development. What is taken into account, in advance, is the need to identify the working class with the needs pointed out as belonging to the whole of Brazilian society, represented by the bourgeoisie, and the defense of the political and economic interest of the national State, along the lines of the model neoliberal. For those who dare to revolt, deconstructing this bridge is the historic challenge that is set in the present time.

\section{PALAVRAS-CHAVE}

Discurso neoliberal. "Uma ponte para o futuro". Efeitos de sentido.

\section{KEYWORDS}

Neoliberal discourse. "A bridge to the future". Sense effects.

\section{Introdução}

Este artigo trata do discurso neoliberal e se inscreve sob uma base teórica materialista filiada às formulações apresentadas por Michel Pêcheux, particularmente à última fase de desenvolvimento de seus estudos. É nesse sentido que nos interessa a relação inseparável entre língua, história e ideologia, tendo em conta que o sujeito é produzido pela ideologia e só existe como resultado de processos de interpelação ideológica, não preexistindo a ela.

Para a vertente pecheuxtiana, o discurso acontece na articulação de um dado momento a uma rede de memórias, portanto, "é índice de agitação nas filiações sócio-históricas" (PÊCHEUX, 2015, p. 56), tendo em conta que o processo sócio-histórico da formação social capitalista sustenta o antagonismo de classes, a reprodução das relações de produção e dissimula as contradições sociais. Ao entender o discurso como prática social, a Análise do Discurso o toma como um movimento do ser humano e sua história, numa imbricação de sentidos produzidos e determinados. A partir do 


\section{REVISTA DA ABRALIN}

funcionamento discursivo, é possível identificar os processos de deslocamento de sentidos, em seus diversos espaços de interpretação e construção.

Ao analista está posto, então, o texto como objeto de sua observação, enquanto materialidade do discurso. Assim, o discurso é o objeto teórico e o texto é o objeto analítico, o que permite ao analista o movimento, não de interpretação do texto, mas de interrogação da interpretação (ORLANDI, 2017). Segundo Amaral (2007), uma análise de discurso implica, então, em descrever e interpretar o funcionamento discursivo. Desse modo, deve haver "uma mediação na relação linguagem/pensamento/mundo que se materializa pela interpretação [...] e que se liga, teoricamente, ao funcionamento da ideologia" (ORLANDI, 2017, p.206).

Considerando o corpus discursivo como "um conjunto de sequências discursivas, estruturado segundo um plano definido com referência a um certo estado das condições de produção do discurso" (COURTINE, 2014, p.114), tomamos inicialmente como recorte da materialidade discursiva o documento "Uma ponte para o futuro", a partir do qual foram feitas articulações com outros recortes, a exemplo de reportagens e imagens, o que possibilitou a formulação de um corpus de análise, com o objetivo de ressaltar a opacidade da linguagem a partir dos efeitos de sentido do discurso neoliberal no Brasil.

A exposição da análise empreendida inicia trazendo a relação do Estado Brasileiro com o neoliberalismo e a austeridade; em seguida, são analisados os efeitos de sentido da retirada da letra "P" da legenda partidária PMDB, e a partir do documento "Uma ponte para o futuro" são analisadas sequências discursivas que mobilizam teoria e método no nosso gesto de interpretação. Com base na postura teórico-metodológica e política aqui assumida, busca-se desvelar as contradições históricas a partir dos domínios de antecipação, atualidade e memória (COURTINE, 2014) e como estes domínios determinam a representação do real face às investidas do neoliberalismo dentro da formação social capitalista brasileira.

\section{Estado neoliberal, austeridade e representação do político}

A história da modernidade se confunde com a história da formação dos Estados Nacionais e a difusão do modo de produção capitalista. A partir das expedições ultramarinas surgiram espaços públicos de disputas políticas, possibilitando, assim, o estabelecimento do capitalismo nos moldes de como se conhece. O Estado se estabeleceu como manifestação política do capital, e esta, por sua vez, possibilitou a organização das forças produtivas sob o regime de propriedade privada em um emaranhado de regras e condutas que estabelecem e perpetuam as relações entre classes sociais, e sua finalidade maior é a viabilização da economia de mercado (JINKINGS, 2015). Desse modo, o Estado é necessário ao capitalismo, não sendo ocasionalmente capitalista, mas necessariamente capitalista, existindo apenas sob a lógica do capitalismo. Ao ancorar-se na forma política dos agentes de produção, o Estado reflete a forma-mercadoria, as formas de relações sociais (MASCARO, 2015). 


\section{REVISTA DA ABRALIN}

Por sua vez, o Estado capitalista brasileiro é resultado da reorganização político-administrativa e da crescente expansão urbano-comercial-industrial, decorrente da transição de uma ordem social escravocrata e senhorial para um estágio de ampla difusão de técnicas, valores e instituições sociais da política de mercado capitalista (FERNANDES, 2011). Depois da década de 1930, a burguesia brasileira, outrora escravocrata, passou por uma crise do seu poder político, pressiona da pelas estruturas e dinamismo do capitalismo monopolista mundial, que ameaçaram os seus interesses econômicos. Entretanto, um elemento político explícito emanou desse processo de tensão: a ratificação da permanência de condições precisas que assegurassem os interesses da classe dominante e possibilitassem o desenvolvimento com segurança de garantias econômicas, sociais e políticas ao capital estrangeiro e suas empresas, e ao seu crescimento (FERNANDES, 2011).

Nessa perspectiva, o Estado brasileiro traz consigo a marca inerente ao modo de produção capitalista, a sucessão de ciclos de crises, pois "não existiu, não existe e não existirá capitalismo sem crise" (NETTO; BRAZ, 2012, p.170). É o que se observa com a crise de $1990^{1}$, uma crise da hegemonia burguesa, na qual seu projeto de classe social é posto em xeque, estando arraigada às crises globais do capital, bem como à deterioração das relações de trabalho, na periferia e no centro do mundo globalizado (BATISTA, 2015).

No Brasil, o Estado adotou a ideologia do neoliberalismo como política econômica, na tentativa de superar os efeitos da crise estrutural do capital no país. De acordo com Guilbert (2020), a ideologia neoliberal apoia-se no conceito de rentabilidade ao curto prazo e no quadro matemático e econômico geral para produzir a tópica da eficácia, a rentabilidade financeira e, ao objetivá-la, a austeridade apareceu como um braço executor das reformas necessárias para o retorno ao crescimento econômico.

Tem-se, então, o deslocamento do sentido de austeridade ressurgindo como algo novo, próprio da formação discursiva da economia. No entanto, sua filiação remonta à formação discursiva da filosofia e da moral, especialmente para intensificar um estilo rígido, disciplinador, compatível com sacrifícios, parcimônia, prudência e sobriedade, a fim de reprimir comportamentos dispendiosos, insaciáveis, perdulários. Este discurso produz sentido de moral, deslocando características próprias do indivíduo para o plano público, personificando e atribuindo características humanas ao Estado (DWECK et al., 2018).

O argumento contemporâneo para o termo austeridade sustenta que, para crises econômicas, devem ser implantadas políticas fiscais restritivas, ou seja, redução de gastos e aumento de impostos, assegurando um aumento do crescimento econômico e efeito expansionista. Na prática, a austeridade como política se estabelece com o corte de gastos com consequente perda de direitos (BLYTH, 2017).

Todos os esforços se voltaram para a justificativa de um social-liberalismo, como um primo bem-intencionado do neoliberalismo, mas que trazia no seu âmago as exigências do capital sob a bravata de estar à frente de uma transformação socioeconômica gigantesca, que perduraria por anos. Nesse sentido, o Banco Mundial, nos anos de 1990, defendeu a revisão da premissa

\footnotetext{
${ }^{1}$ O Brasil foi alvo da crise do Plano Collor, que ficou marcada por um profundo momento de recessão econômica e confisco dos ativos depositados nas cadernetas de poupança dos brasileiros.
} 


\section{REVISTA DA ABRALIN}

constitucional, que atribui um papel de complementaridade ao setor privado no âmbito do sistema e sugeriu que o Brasil realizasse reformas que favorecessem maior participação do setor privado na economia (RIZZOTTO, 2012). É com base nesses pressupostos que avançaremos, dando ênfase a uma abordagem discursiva sobre a representação do político, considerando que o discurso aparece como extrato de diversos funcionamentos discursivos e, como tal, traz em si a relação com diferentes formações discursivas. É dessa forma que ele é tocado pela política e pelo político.

Na demarcação tradicional entre política e político, considera-se a política como governabilidade com a sociedade envolvida, retoricamente definida como a arte de falar pelos outros. No âmbito da política partidária, esta se faz pela estruturação de forças em torno de programas de grupos de poder, portanto, de diferentes distribuições e desenhos sócio-políticos. Trata-se, por conseguinte, o político como a divisão necessária de sujeitos e sentidos, na sua determinação histórico-social, e, na especificidade desta análise, sujeitos pensados na conjuntura capitalista. O político é, então, significado por relações que simbolizam o poder, organizando-se no nível da significação pelas relações entre formações discursivas, não se separando das formações ideológicas, o que implica ser o político da ordem do discurso (ORLANDI, 2019). Considerando-o como relação simbólica de forças, nele os sentidos adquirem direções determinadas pela forma de organização social que se impõe a um indivíduo ideologicamente interpelado (ORLANDI, 2001).

Dessa maneira, o discurso político se constitui na persuasão, movendo a opinião pública, os eleitores e a população em geral, ancorando-se em uma formação discursiva que atribui posições não apenas aos oradores autorizados, mas a todos os oradores, incluindo os de outras formações (CORTEN, 1999). Ideologicamente, produz-se uma ilusão política: "somos 'representados', há sujeitos, ou melhor, posições-sujeitos 'autorizadas' a falar, ou que falam, por nós, em nossa formação social" (ORLANDI, 2019, p.27, grifo da autora). Por isso, ao se falar como se fosse do lugar do outro, partidos políticos, como o MDB, elaboram documentos ${ }^{2}$, propõem medidas de livre mercado, de austeridade, ou um vice-presidente da República elabora Carta aberta à nação ${ }^{3}$. Trata-se de um processo de autorização, que acontece no interior de uma formação discursiva, na qual se realiza o "assujeitamento" do sujeito ideológico do discurso.

Considerando que as palavras e proposições têm seus sentidos a partir e nas formações discursivas nas quais são produzidas, em se tratando do referido partido político, poderíamos perguntar, inicialmente, quais os sentidos produzidos pela retirada de uma letra de uma sigla partidária?

Entendemos tratar-se de um movimento que se constitui no domínio de antecipação, considerado dentro do funcionamento discursivo como prática social, uma vez que o sujeito do discurso se antecipa ao seu interlocutor, quanto ao sentido que suas palavras nele produzem, ou seja, dir-se-á isso ou aquilo, a partir do efeito que se pensa poder produzir em seu ouvinte (ORLANDI, 2015). "É pelo domínio de antecipação que buscamos um 'sempre-já” (COURTINE, 2014, p.113, grifo do autor)

\footnotetext{
${ }^{2}$ Caso do Documento "Uma ponte para o futuro", no qual são apresentadas diretrizes e recomendações para a então presidenta Dilma Rousseff, no período pré-impeachment.

${ }^{3}$ Carta do vice-presidente Michel Temer para a então presidenta Dilma Rousseff.
} 


\section{REVISTA DA ABRALIN}

do discurso, e, além disso, "acrescentemos que ao antecipar temos um 'sempre-ainda"' (COURTINE, 2014, p.113). Desse modo, a retirada da letra "P" é uma antecipação aos efeitos de sentido quanto aos gestos de intepretação que se façam sobre um partido político.

Nessa lógica, o Partido do Movimento Democrático Brasileiro (PMDB), em uma convenção extraordinária, ocorrida em 19 de dezembro de 2017, aprovou a retirada da letra "P" da sigla do partido, passando a legenda a ser chamada pelo nome original MDB. Destaca-se que a retirada do "P", e a retomada ao nome original à época dos movimentos pró-democracia da década de 1980, foi uma medida com a intenção de diminuir o desgaste do PMDB, bem como da política partidária junto à sociedade, e popularizar a legenda. No entanto, tal medida funciona discursivamente como uma tentativa de apagamento do golpe de 2016, uma vez que ao retomar a sigla à época de sua criação, que coincide com o pluripartidarismo, pretende-se marcar uma posição ideológica do partido com a democracia, afastando-se do processo de impeachment, enquanto ato antidemocrático, negando em si mesmo sua posição-sujeito do discurso. Tenta-se silenciar, dessa maneira, o papel que Michel Temer teve contra a democracia brasileira no curso do golpe jurídico-parlamentar de 2016.

Assume-se um compromisso, agora partidário, com o mercado ao qual são atribuídas virtudes que de modo equidistante são defeitos para o Estado. A "liberdade" da democracia é a liberdade de mercado, diante da qual a presidenta Dilma Rousseff era um empecilho, devendo-se considerar que ao mercado compete abertura, flexibilidade, movimento, dinamicidade. Por sua vez, na perspectiva do discurso, "a produção de efeitos de atualidade é ao mesmo tempo uma resultante do desenvolvimento processual dos efeitos de memória, que a irrupção do acontecimento, no interior de uma conjuntura, reatualiza" (COURTINE, 2014, p.113).

Em termos precisos, o domínio da atualidade se refere "ao funcionamento do discurso em relação a si mesmo" (PÊCHEUX, 2014, p.153), tendo relação com a coexistência de outros dizeres, o que se diz, pois, em um dado corte no tempo, em uma linearidade horizontal inerente ao enunciado. "[N]esse sentido, o sujeito opera imprimindo sua marca, estabelecendo a diferença entre o que diz, a forma, o estilo, e os outros dizeres. Esse é o eixo de denominação do intradiscurso" (AMARAL, 2007, p.31, grifo da autora). O intradiscurso pode ser denominado como "o que eu digo agora, com relação ao que eu disse antes e ao que eu direi depois, portanto, o conjunto de fenômenos de 'co-referência' que garantem aquilo que se pode chamar de 'fio do discurso', enquanto discurso de um sujeito" (PÊCHEUX, 2014, p.153, grifo do autor).

Assim, o retorno da sigla do partido à designação "MDB" tenta encarnar um "movimento" em prol do futuro, da novidade, do crescimento, da diversidade, da autenticidade, enquanto à designação PMDB é atribuída relação político-partidária de submissão ao Estado, postura que se quer abandonar, por estar associada às restrições legais, à rigidez da máquina estatal, ao imobilismo arcaico do Estado (GUILBERT, 2020). Desse modo, no processo discursivo, ao retomar ao passado, vislumbra-se o futuro.

Tendo em conta que as condições de produção permitem o funcionamento discursivo e compreendem fundamentalmente os sujeitos e a situação, podem ser consideradas "as condições de produção em sentido estrito e temos as circunstâncias da enunciação: é o contexto imediato" (ORLANDI, 2015, p.28). Em se tratando das condições amplas de produção do discurso em tela, 


\section{REVISTA DA ABRALIN}

considerando que após a crise financeira global o cenário econômico em mudança tornou difícil conciliar os interesses da burguesia, aponta-se a nova política econômica, a recessão cíclica e a insatisfação do empresariado.

No Brasil, em 2014, o disfarce de crise política culminou com o impeachment da então presidenta Dilma Rousseff. Naquele contexto, as motivações ideológicas encontraram força em setores decisivos da economia, para iniciar as reformas com o objetivo de "salvar" o Estado capitalista brasileiro, ocasião em que o governo subsequente adotou o documento "Uma ponte para o futuro", cujo objetivo era "preservar a economia brasileira e tornar viável o seu desenvolvimento..." (PMDB, 2015).

O objetivo, também, era eliminar o rentismo da dívida pública como meio sistemático de acúmulo de capital (a maneira mais importante de ganho da burguesia brasileira desde o início dos anos 1980) e, assim, forçar a expansão dos investimentos produtivos e de infraestrutura. Isso permitiu que a força estrutural do capital financeiro se apresentasse como meramente técnica e não profundamente política, incluindo o uso de controles da grande mídia para designar a política econômica como "tecnicamente irresponsável" e "politicamente populista" (BASTOS, 2017).

Por seu turno, o projeto governamental tinha como objetivo principal a eliminação, ou na pior das hipóteses, a minimização do rentismo com dívida pública como meio sistemático de acumulação de capital. Isso significava pôr em dúvida a força estrutural do capital financeiro na determinação das taxas de juros e das taxas de câmbio, violando pactos conservadores de outrora (BASTOS, 2012). Assim, a promoção do populismo de direita no Brasil se apoiou em uma revolta da classe média que se viu diante dos custos dos serviços privados afetados, da falta de emprego e do crescimento das camadas mais pobres da sociedade, o que para a referida classe seria decorrente do populismo e da demagogia dos políticos que compraram apoio às políticas sociais que eles custearam.

Políticos e empresários envolvidos em transações ilegais tinham interesse evidente em substituir um governo por outro que fosse capaz de barrar ou limitar as suas apurações. A unificação empresarial contra o governo Dilma, de um lado, e a perda de sua popularidade, de outro, seria resultado de processos e eventos ocorridos depois do resultado das eleições de 2014.

Sabemos que em escala planetária, a burguesia tende a preferir a interação social governada exclusivamente pelas assimetrias monetárias e de mercado, ficando menos convencida do que forçada a aceitar uma cidadania ampliada, ou seja, a invasão dos direitos sociais no capitalismo. Isso pode ser ainda mais evidente no caso do Brasil, devido às profundas desigualdades geradas pelo projeto escravocrata que orientou o desenvolvimento social. É nesse contexto que em março de 2015, dentre dos inúmeros protestos contra o governo Dilma, dois fantoches representando Lula e Dilma enforcados, pendentes em um viaduto foram noticiados por diversos veículos de comunicação (FIGURA 1). 


\section{REVISTA DA ABRALIN}



FIGURA 1 - Bonecos de Lula e Dilma sendo enforcados num viaduto. Fonte: Sul21 (2015)

As condições de produção que possibilitaram a cena materializada na imagem apontam para um contexto em que a classe dominante não conseguia mais admitir a perda do poder e privilégios de toda sorte, ao longo de mais de 12 anos de governos do PT. Produz-se, então, um efeito-intolerância, a exemplo do protesto, ocorrido em março de 2015, que pedia o extermínio físico da presidenta, de petistas, comunistas e esquerdistas em geral. Cabe considerar que, na imagem anteriormente apresentada, a figura do ex-presidente Lula foi recuperada devido a sua relação com a presidenta Dilma. Para além de serem do mesmo partido político, a presidenta foi ministra de Minas e Energia do Governo Lula e foi fortemente apoiada por ele nas campanhas presidenciais de 2010 e 2014, além dele ser apontado como seu potencial sucessor. Entretanto, a figura de um boneco do ex-presidente pode ser apreendida também enquanto efeito de sentido de um discurso de gênero, uma vez que, pela memória, a mulher (Dilma) também foi associada a uma posição de submissão, de coadjuvante do homem (Lula), como se a presidenta não tivesse autonomia, não conseguisse tomar decisões, como se o seu lugar não fosse a presidência. Nessa esteira, Dilma aparece como figura política produzida por Lula, como seu fantoche, cuja sentença deveria ser igual a de seu "criador".

É expresso, assim, um ressentimento, enquanto efeito estrutural da soberania excessiva do outro (no caso dos partidos de esquerda), da "consolidação fantasmática" (DUNKER, 2015, p. 66). Observamos, então, como o ressentimento prospera naqueles que se sentem excluídos (classe dominante). Para a classe dominante, "é como se a senzala tivesse invadido a casa grande e dela se apropriado" (INDURSKY, 2016, p. 80). Desse modo, estavam postas as condições objetivas para a unificação da burguesia em torno de um programa regressivo que, finalmente, aconteceria caso uma alternativa política viável ao governo aparecesse, o que ocorreu quando, de dentro dele, Michel Temer anunciou o programa "Uma Ponte para o Futuro" (BASTOS, 2017).

O documento intitulado "Uma Ponte para o Futuro" foi apresentado em 29 de outubro de 2015, como um programa de preservação da economia brasileira, capaz de tornar viável o seu desenvolvimento. É dividido em títulos voltados à explanação do raciocínio que justificava as mediadas propostas pelo partido PMDB. Ao trazer "Um retrato do presente", por exemplo, o documento tenta situar o leitor no quadro de crise que afligia o Brasil; em "A questão fiscal" são apresentados déficits elevados e tendência ao endividamento do Estado; em seguida, "Retorno a um orçamento verdadeiro" sinaliza a necessidade de cortes nos gastos públicos"; em "Previdência e demografia" há uma 


\section{REVISTA DA ABRALIN}

tentativa de culpabilizar o envelhecimento da população brasileira pelos gastos com aposentadorias, mostrando um posicionamento a favor de uma reforma da Previdência mais radical; em "Juros e Dívida pública", faz-se referência à inflação e à meta para seu controle, vinculando-a à queda do juros, reafirmando a necessidades de reformas estruturais; o último tópico do documento, por sua vez, propõe "Uma agenda para o desenvolvimento", no qual as medidas de austeridade e a aproximação com a iniciativa privada são explicitadas.

Além do referido documento, assumiu relevância na cena política brasileira, uma Carta pessoal do então vice-presidente Michel Temer endereçada à presidenta Dilma Rousseff, aos 7 dias do mês de dezembro de 2015, na qual Temer utiliza como subterfúgio uma desconfiança da presidenta e de seu entorno para com ele e com o seu partido, o PMDB. Na referida carta, Temer diz que ocupou uma posição meramente decorativa, reclama dos ministérios perdidos pelo seu partido, faz cena de ciúmes, e menciona que “o programa 'Uma Ponte para o Futuro', aplaudido pela sociedade, cujas propostas poderiam ser utilizadas para recuperar a economia e resgatar a confiança foi tido como manobra desleal" (TEMER, 2015). Estava ali rompida a unidade partidária PT/PMDB, e explicitado que o governo Dilma não servia mais aos interesses do capital: "Jamais eu ou o PMDB fomos chamados para discutir formulações econômicas ou políticas do país; éramos meros acessórios, secundários, subsidiários" (TEMER, 2015). Em outro trecho, é possível notar a preocupação com o ajuste fiscal: "Quando a senhora fez um apelo para que eu assumisse a coordenação política, no momento em que o governo estava muito desprestigiado, atendi e fizemos, eu e o Padilha, aprovar o ajuste fiscal. Tema difícil porque dizia respeito aos trabalhadores e aos empresários" (TEMER, 2015).

Sendo o ajuste fiscal um "tema difícil porque dizia respeito aos trabalhadores e aos empresários", é possível identificar na linguagem, enquanto um ato social, as suas implicações, neste caso, os conflitos e as relações de poder, a luta de classes. O que escapa no referido dizer é o "antagonismo entre classes opressoras e classes oprimidas. Mas para oprimir uma classe é preciso garantir condições tais que lhe permitam pelo menos uma existência servil" (MARX; ENGELS, 2010, p. 63), o que reclama a necessidade da perpetuação de políticas que favorecessem o empresariado, mas que, ao mesmo tempo, simulassem coerência aos direitos dos trabalhadores.

Desse modo, o motivo para a ruptura PT/PMDB estava posto, mas as motivações nem tanto. Com o abandono ao governo Dilma, o terreno estaria pronto para as reformas, e, portanto, expressões como "ajuste fiscal", "recuperar a economia", "resgatar a confiança", "crescer e consolidar", presentes na referida Carta, inscritas numa formação discursiva neoliberal, permitiriam um funcionamento discursivo que fizesse ecoar um já-dito de um "Brasil, país do futuro".

Cabe ressaltar que o enunciado "Brasil, um país do futuro" aparece pela primeira vez como título do livro do escritor vienense Stefan Zweig.

\footnotetext{
Seu desejo de querer ver no Brasil da década de 1940 uma terra livre das intolerâncias e violências que assolavam a Europa de então, fustigada pela $2^{\text {a }}$ Guerra Mundial, fez com que Zweig revivesse a imagem mitológica de que o Brasil era uma terra paradisíaca, um éden reencontrado. A descrição que faz do Brasil, mais que otimista, adquire um aspecto profético quando o autor reforça que a harmonia e paz reinantes no país faziam deste o locus para o acontecimento de um futuro utópico, messiânico. Curiosamente o escritor/profeta, muitas vezes, trai suas profecias, projetando no Brasil valores de sua
} 


\section{REVISTA DA ABRALIN}

Europa e às vezes chega mesmo a se contradizer no que tange à questão da tolerância e harmonia que via no Brasil (CARVALHO, 2006, p.30).

No funcionamento discursivo do enunciado "Brasil, país do futuro", a formação discursiva de referência (o discurso político) foi analisada considerando os domínios de memória, de atualidade e do domínio de antecipação (COURTINE, 2014), bem como o interdiscurso, enquanto um "conjunto complexo e contraditório [...] das formações discursivas em jogo numa dada formação social sob a dominação do conjunto das formações ideológicas" (AMARAL, 2007, p.24). Nesse percurso, partimos do domínio de memória para apreender o funcionamento discursivo do discurso neoliberal no discurso político, por meio do encaixe do pré-construído, a representação do interdiscurso (COURTINE, 2014).

\section{2. "Uma Ponte para o Futuro": memória, história, evidência}

A primeira das três sequências discursivas (SD) em análise foi extraída do próprio título do documento ( $\mathbf{S D}_{\mathbf{1}}$ - "Uma Ponte para o Futuro"), tratando-se de um enunciado que aparece durante um momento específico da crise estrutural do capital no Brasil, sob o disfarce de uma crise política. Na imediaticidade do dizer, a palavra "ponte", em um sentido pretensamente estabilizado, consiste em uma construção que permite cruzar um obstáculo natural (desnível topográfico, cursos de rio, braços do mar) ou uma estrada pela qual outros veículos circulam. A esta definição estão associadas outras menos genéricas que estabelecem alguma característica específica, tais como viaduto - obra de grande altura e comprimento até transformar a ponte em uma passagem alta e apoiada em pilares ou outros suportes descontínuos (ZOIDONARANJO et al., 2000).

No entanto, em nosso gesto de análise, o sentido de "ponte" vai além de uma estrutura arquitetônica, pois, antes de tudo, "é necessário lembrar que, no discurso, é a palavra que assegura a função de identidade semântica: é essa identidade que a metáfora altera" (RICOUER, 2000, p.11). Nessa perspectiva, "a metáfora apresenta-se, então, como uma estratégia de discurso que, ao preservar e desenvolver a potência criadora da linguagem, preserva e desenvolve o poder heurístico desdobrado pela ficção" (RICOUER, 2000, p.13).

Uma noção imediata de "ponte" remete ao que ela pode proporcionar, levar de um lugar ao outro, superar barreiras, transpor obstáculos, realizar uma ligação de uma época a outra. Na referida SD, mesmo sem a existência de um verbo, há uma ideia de movimento, abrindo-se espaço, portanto, para o silenciamento de outro caminho que deve ficar para trás, o que as condições imediatas do discurso permitem identificar: a restrição do campo da "esquerda", que na relação com futuro é associada ao fracasso da economia (no tempo presente).

Em sua relação constitutiva com a ideologia dominante, a produção de sentido de unicidade, na relação do político com a prática política, produz a ilusão, ao "falar do outro", que só há um caminho, 


\section{REVISTA DA ABRALIN}

uma direção, uma ponte, entre o presente e o futuro, nos moldes apresentados pela pauta neoliberal, materializados no documento "Uma Ponte para o Futuro".

Do ponto de vista metafórico, o enforcamento de Lula e Dilma num viaduto, conforme anteriormente abordado, é expressão não apenas de um julgamento negativo dos governos do PT, mas, sobretudo, da condenação máxima, a forca, penalidade abolida no Brasil desde 1937, possível apenas em situação de guerra. Pondo em relação o viaduto e a ponte, nas metáforas que os constituem, alinham-se à perspectiva econômica os efeitos imediatos da crise estrutural do capital, deslocados para o campo político da administração petista no país. Desse modo, contribui-se para a produção de intolerância, enquanto efeito da relação entre diversos elementos de saber que circulam nos processos discursivos (corrupção, comunismo, socialismo, ideologias, esquerda, etc.), constituídos entre a forca e o futuro.

Por seu turno, o simbolismo do enforcamento no discurso funciona como operador de uma memória social, comportando no interior dela mesma um programa de leitura, um percurso escrito discursivamente em outro lugar, onde na transparência de sua compreensão a imagem se mostra como ela se lê (PÊCHEUX, 2007). Ora, um viaduto com duas personalidades de esquerda enforcadas é lido como um linchamento simbólico e sinaliza um caminho único, no qual o viaduto liga o desejo da classe dominante à morte física e ideológica de seus adversários políticos.

Ao ligar uma época à outra, a ponte faz referência ao futuro, cuja noção só se dá na sua relação constitutiva com a demarcação do presente e do passado, pondo em perspectiva um processo histórico que se materializa no discurso. De acordo com Guimarães, numa abordagem histórica da linguagem "não é o sujeito que temporaliza, é o acontecimento. [...] O sujeito é tomado na temporalidade do acontecimento" (GUIMARÃES, 2017, p.16). Para o referido autor, portanto, o tempo é uma representação na qual "o presente traz uma latência de futuro, que, no acontecimento, projeta sentido, significa porque o acontecimento recorta um passado como memorável" (GUIMARÃES, 2017, p. 16).

Em se tratando de temporalidade, a exemplo do sentido de futuro na SD1, cabe perguntar:

E o que é essa temporalidade? De um lado ela se configura por um presente que abre em si uma latência de futuro (uma futuridade), sem a qual não há acontecimento de linguagem, sem a qual nada é significado, pois sem ela (a latência de futuro) nada há aí de projeção, de interpretável. [...] Por outro lado este presente e futuro próprios do acontecimento funcionam por um passado que os faz significar. [...] Esse passado é, no acontecimento, rememoração de enunciações (GUIMARÃES, 2017, p.16, grifo do autor).

O futuro é, pois, um efeito de atualização na memória, investido do interdiscurso. É, antes de tudo, um espaço móvel de divisões, de disjunções, de deslocamentos e retomadas de conflitos e regularização, um espaço de réplicas e contradiscursos (PÊCHEUX, 2007), e que traz, também, uma negação implícita: o que virá a ser ainda não é, uma vez que o futuro só existe enquanto perspectiva. Em termos mais precisos, trata-se de um futuro que constitui o sujeito a partir de uma projeção imaginária, que é projeção do desejo.

Esse o que virá a ser ainda não é, como também essa projeção do desejo, abre uma latência para algo que nunca chega, que nunca acontece. É esse tempo sempre esperado um elemento fundamental ao discurso religioso, que se materializa como esperança. Em se tratando de um presente caótico, 


\section{REVISTA DA ABRALIN}

exemplificado pelo viés da economia, enquanto um tempo de escassez financeira, projeta-se a imagem de um futuro de prosperidade, com ancoragem, por exemplo, numa teologia que defende a bênção financeira como desejo de Deus e a fé, a resignação e as doações para os ministérios cristãos, como meios para aumentar a riqueza material do fiel. Por sua vez, o discurso messiânico materializa a espera do que está por vir, circulando no imaginário social para produzir sentidos da necessidade de um Messias. No plano político brasileiro, esse imaginário é recuperado para lhe atribuir a responsabilidade de acabar com a corrupção, com a velha política, com a exigência de superação da crise, bem como o desejo pelo milagre econômico.

Do ponto de vista discursivo, esse imaginário social continua a produzir sentidos porque surge como um recorte de um passado memorável, um deslizamento de discursos outros (FIGURA 2), que remontam a campanhas políticas eleitorais que, de maneira semelhante ao que vimos no Brasil em 2018, vislumbravam o desenvolvimento econômico: "50 anos em 5" (campanha eleitoral de Juscelino Kubitschek, 1955); "Collor é progresso. Um novo tempo vai começar" (campanha eleitoral de Fernando Collor, 1989); "O Brasil não pode voltar para trás. Avança Brasil" (campanha eleitoral de Fernando Henrique Cardoso, 1998).

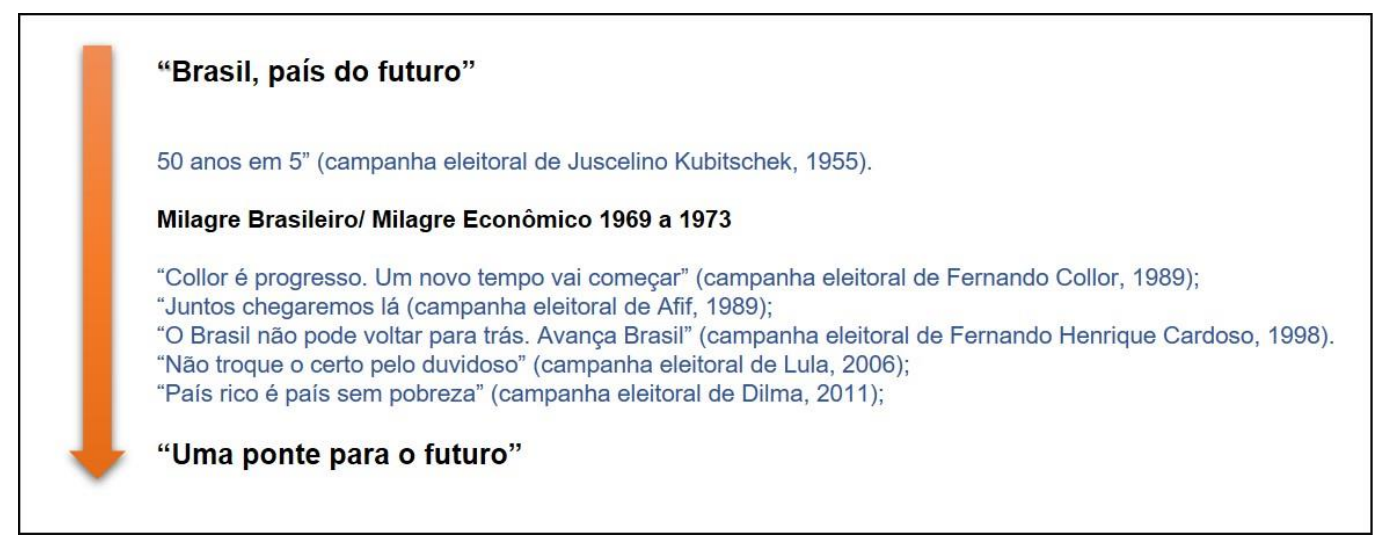

FIGURA 2 - Deslizamento discursivo do enunciando "Uma ponte para o futuro". Fonte: Elaborado pelos autores.

No processo discursivo de retomada desses dizeres, observa-se uma sobreposição dos domínios de atualidade e memória, na SD1 - "Uma ponte para o futuro". O papel da memória seria o de fixar um sentido sobre os demais enunciados, também possíveis, em uma dada conjuntura histórica. Mais especificamente, é o domínio da memória que reserva um espaço para a organização da linearidade entre passado, presente e futuro (domínio de atualidade), contribuindo para a manutenção da diacronia interna de uma formação social (MARIANI, 2001).

Desse modo, o domínio de memória atualiza o enunciado "Brasil, um país do futuro", situando-o no campo do discurso político, como um Novo Mundo onde estaria o paraíso perdido, um Brasil, desprovido "da cultura histórica do velho continente, mas aberto ao futuro, ao desenvolvimento" (CARVALHO, 2006, p.34), como também "uma nova terra, fértil, vazia de gente, livre, aberta ao estrangeiro" 


\section{REVISTA DA ABRALIN}

(CARVALHO, 2006, p.37), inscrevendo-se como propostas políticas para consolidação do Estado neoliberal a fim de garantir a construção de um Estado moderno, próspero e justo (MASSMANN, 2019).

Nessa direção, tomamos o deslizamento discursivo (FIGURA 2) do enunciado "Brasil, país do futuro", produzido sob as condições políticas-ideológicas que antecederam a $2^{\text {a }}$ guerra mundial, mais precisamente na década de 1940, formulado por um judeu que enxergava o Brasil como a terra fértil para o desenvolvimento, como seu ideal de futuro. O realce em negrito marca a circulação desse enunciado em diversos momentos da política brasileira e a partir do efeito parafrástico, tal enunciado se atualiza em "Milagre Brasileiro/Milagre Econômico" (que circulou de 1969 a 1973, durante os governos ditatoriais), para designar o elevado crescimento econômico, aumento do Produto Interno Bruto (PIB), queda da inflação e a formação dos grandes conglomerados brasileiros.

Os sentidos oriundos desse enunciado circulam produzindo efeitos nas diversas campanhas eleitorais como demonstramos até chegarmos à linearidade do dizer "Uma ponte para o futuro", tratando-se, portanto, do velho revestido do novo. É dessa maneira que o encontramos presente ao longo da formação social brasileira, na qual a preocupação com a economia foi e continua sendo a parte que interessa à organização social capitalista.

Por sua vez, na $\mathbf{S D}_{2}$-"Uma agenda para o desenvolvimento", extraída do título do último tópico do documento "Uma ponte para o futuro", deparamo-nos com a presença de uma formação discursiva neoliberal, para a qual a agenda remete a compromissos, a metas, fazendo parte do dia a dia de executivos, das grandes corporações capitalistas, denotando, pois um sentido de rotina, de circularidade e da racionalidade aparente do discurso neoliberal. A agenda transmite uma naturalidade dos acontecimentos, que devem seguir uma sequência lógica, previamente estabelecida, e apresenta como racional "deixar o mercado fazer", o "laissez-faire 4 " (GUILBERT, 2020).

Deixar o mercado fazer significa que a escolha das palavras e expressões não é anódina, uma vez que as palavras utilizadas propõem uma determinada leitura de mundo. A agenda nos remete, ainda, a uma permissão de programação das ações humanas subordinadas a tudo que seja delas oriundo em uma dimensão estritamente econômica. Para Guilbert (2020), é neste ponto que o discurso neoliberal e o discurso econômico se encontram, são considerados intercambiáveis.

O encontro dessas duas formações discursivas, neoliberal e econômica, induz a aceitar tornar produtivo, no sentido econômico, o que não pode sê-lo: a Educação, a Saúde, a Previdência. São suas palavras-chave: "ajuste fiscal", "restruturação das despesas públicas", simplificação da "área tributária", "redução de tarifas", "realinhamento do câmbio", "abertura dos mercados externos", "comércio internacional", "investimento privado", "licenciamentos ambientais" (PMDB, 2015) - que estão presentes no tópico do documento que utilizamos na formulação da SD2, para efeito de análise, evidenciando o discurso neoliberal e econômico.

\footnotetext{
4 "Doutrina que - quaisquer que sejam os fundamentos - divinos, científicos ou naturais -, afirmava que o campo de ação do Estado devia ser estritamente definido e que a vida econômica devia ser deixada, o menos regulamentada possível, aos talentos e ao bom senso de cidadãos privados movidos pelo honrado objetivo de fazer seu caminho na vida" (KEYNES, 1926, p. 8, apud GUILBERT, 2020, p.86).
} 


\section{REVISTA DA ABRALIN}

Todos esses compromissos propostos na agenda, supostamente, têm por objetivo um bem maior, o milagre econômico, através do que considera desenvolvimento. Sob o manto ideológico de um compromisso com o futuro do Brasil, faz-se necessário produzir no senso comum a evidência de um discurso que silencia, no campo político, as determinações econômicas do discurso neoliberal. A partir desse silenciamento, toma a forma de um discurso racional de onde advém seu efeito simbólico e argumentativo. Ele significa ao silenciar seu aspecto de programa de "contra-governo petista ${ }^{5 "}$ e é sobre uma base ostentatória e dissimulada que, segundo Guilbert, a forma racional assume seu aspecto de evidência de normalidade e só se pode aderir naturalmente a este discurso devido ao "apelo às paixões" (GUILBERT, 2020, p.46), que "é legitimado e modalizado pelo recurso à racionalidade" (GUILBERT, 2020, p.46).

Desse modo, o desenvolvimento surge como consequência lógica de uma agenda neoliberal de compromissos econômicos a serem assumidos pelo Estado brasileiro. Essa lógica confere um efeito de sentido de naturalidade ao discurso neoliberal, apresentando-o como um discurso apartidário ou esvaziado de ideologia, sustentado na esfera do bom senso e da racionalidade. Na SD2, o desenvolvimento é apresentado como possível de ser acreditado, e, por conseguinte, o ato de crer na evidência do fato apresentado, em sua naturalidade, fornece um quadro natural à situação. Este forma de manipulação da naturalidade, própria do discurso neoliberal, é demonstrada na análise realizada por Guilbert, uma vez que os eventos apresentados,"(i) sendo naturais, eles parecem verossímeis, (ii) não tendo 'causa nem intenção', eles parecem neutros, (iii) determinados por um universo 'puramente físico', parecem inevitáveis" (GUILBERT, 2020, p.84).

Dessa forma, para que a justificativa da implantação da economia de mercado, como a única solução possível para a retomada do crescimento, faça sentido, são necessários deslocamentos oriundos da formação discursiva da economia no discurso neoliberal. Estas evidências discursivas levam os indivíduos a crer que são livres e iguais, sobrepondo as contradições de classes, com os mesmos deveres e diretos a escolhas. A escolha se põe, portanto, entre duas opções: uma que o discurso neoliberal pretende defender (desenvolvimento/futuro) e outra que, por antecipação, supõe que os sujeitos irão rejeitar, uma vez tornada mais aprazível a opção proposta.

O passado, o futuro e a ponte aparecem, então, como uma metáfora do hoje, do presente e, nesse jogo, a opção apresentada pelo discurso neoliberal é adornada por um apelo emocional da necessidade econômica; já a falsa alternativa (crise econômica/passado) é carregada de um sentido de constrangimento. Logo, não há uma escolha real, e a falsa alternativa ecoa: "eu ou o caos" (GUILBERT, 2020, p.127), ou seja, crise econômica/passado ou desenvolvimento/futuro. Mas nesses termos, quem escolherá o caos?

Supostamente tomando partido pelo país, a SD3 - "Convidamos a nação a integrar-se a esse sonho de unidade", última frase do documento "Uma ponte para o futuro", traz um sentido de unidade nacional, fazendo com que, pela memória, evoque-se, o que Orlandi (2009) considera como um

\footnotetext{
${ }^{5}$ Chamaremos de "programa de contra-governo petista", uma vez que quando o documento "Uma ponte para o futuro" foi publicado, o governo vigente era da então presidenta Dilma Rousseff, filiada ao PT, com posições ideológicas distintas do PMDB, partido político que encabeçaria o golpe de 2016.
} 


\section{REVISTA DA ABRALIN}

imaginário romântico de nação, uma concepção positivista, burguesa, moderna de nação (Estadonação). Por sua vez, o sonho do nacionalismo se sustenta na relação com uma união [política] nacional, como se o nacionalismo precedesse a nação, e não o contrário. Desse modo, o sentido de pertencimento de um povo, sob um contexto histórico particular, sustentado por línguas nacionais, faladas ou escritas, forma a nação. Como o nacionalismo se altera no tempo e no espaço, ou seja, na história, é a partir do efeito de memória que se requisita a identificação nacional como um fazer político, como práxis do discurso da ideologia dominante, uma vez que há um sentido já-dado.

Silencia-se, no entanto, um ideário que se constitui enquanto possibilidade de unidade de classes sociais, uma vez que na SD3 observa-se um funcionamento discursivo que pressupõe uma nação [politicamente] desintegrada. Todavia, considerando o momento histórico de crise estrutural do capitalismo, a crise política é necessariamente realçada, enquanto os interesses fundamentais das classes dominantes se voltam, sobretudo, para a retomada do plano de livre mercado, como defendido pelo neoliberalismo.

De acordo com Marx (2008), na formação social capitalista, as relações de classes (antagônicas por natureza) são postas a partir da esfera econômica, como um complexo histórico constituído pela "imbricação de diversos modos de produção, ou da existência de formas provenientes de diversos modos de produção e reestruturada em função da dominância de um dos modos de produção" (ROBIN, 1973, p. 108, grifo da autora). É por esse prisma que consideramos necessário ao funcionamento discursivo neoliberal silenciar, no sonho da unidade nacional, a impossibilidade histórica de conciliação das classes sociais, fundamentalmente, antagônicas. Há, no entanto, a retomada de outros dizeres que recuperam, pela memória nacional, a proposta do integralismo, conforme demonstramos na FIGURA 3.

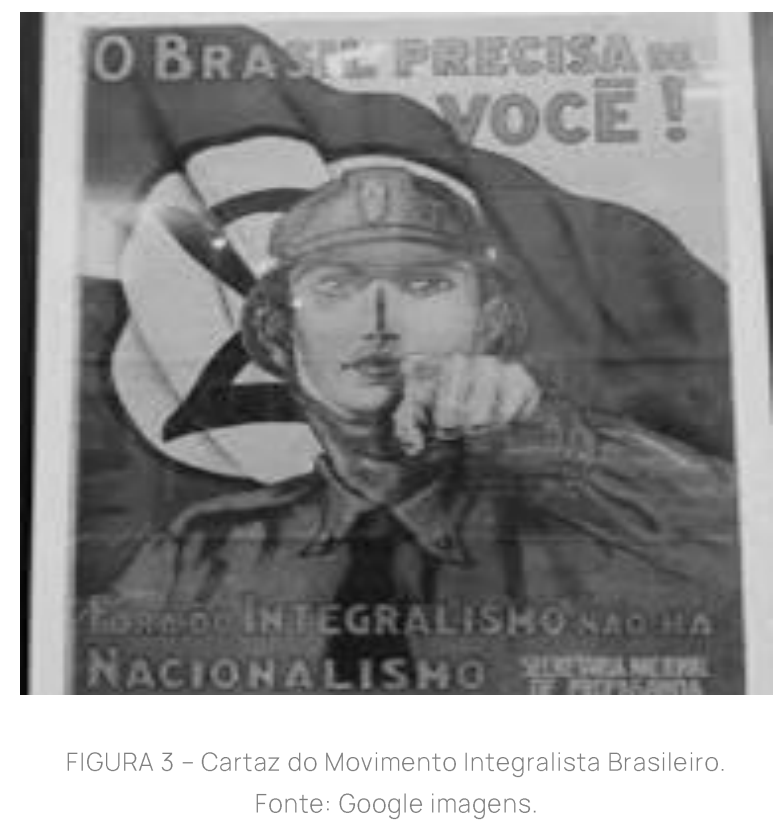




\section{REVISTA DA ABRALIN}

O enunciado recuperado acima - "O Brasil precisa de você" - circulou em cartazes do Movimento Integralista Brasileiro na década de 1930. Segundo Cândido (1978), o referido Movimento tinha caráter reacionário e conciliatório, centrado nos valores e interesses da pequena burguesia parasitária do capitalismo; sob "uma mística sentimental de superfície, um mundo a defender resumido no lema 'Deus, Pátria e Família"' (CHASIN, 1978, p.34, grifo do autor), com elementos essenciais do fascismo, ou de um semi-fascismo verde-amarelo. O dedo em riste, o uso de fardamento, o uso de "você", contribuem para a intimidação do interlocutor, não deixando outra alternativa senão apoiar o integralismo, como condição para o nacionalismo. Todavia, trata-se de um "convite" da classe dominante, simulando evidências de coesão das relações sociais em prol da suposta unidade nacional. Assim, o convite final da última frase do documento "Uma ponte para o futuro", trazido na SD3, transpõe a fronteira do discurso de extrema direita e penetra na memória de um fascismo à brasileira.

Nesse sentido, entendemos o discurso neoliberal como expressão política e ideológica, e o Estado como o meio no qual o capital, a partir de forças materiais, estabelece condições administrativas e legalmente necessárias à reprodução das contradições que o sustentam. Como Engels afirma, "a ação surge sempre de forças diretamente materiais e não das frases que a acompanham; longe disso, as frases políticas e jurídicas são outros tantos efeitos das forças materiais, assim como a ação política e seus resultados" (ENGELS, 2008, p.278).

Nesse sentido, nada parece ser mais necessário para o desenvolvimento do país do que a ofensiva neoliberal contra a classe trabalhadora em seus direitos: reformas trabalhistas, terceirização, redução de investimentos em educação e saúde, privatizações, etc. Contraditoriamente, a classe expropriada dos meios de produção e explorada na sua força de trabalho é convocada a se unir aos seus exploradores para intensificar a sua exploração. O apelo emocional a um sentido de unidade nacional e de homogeneidade entre classes antagônicas é expresso na proximidade e empatia produzida pelos enunciados como: "o Brasil precisa de você" e por efeito parafrástico, "venha fazer parte desse sonho".

Segundo Orlandi (2019), a linguagem é pensada como materialidade, os sentidos como relação e os sujeitos como efeitos-sujeitos. Com base nesses pressupostos, a linguagem não é transparente e não há sentidos ocultos. O que existe é, pois, inconsciente e ideologia. É pelo acesso à ideologia, que consideramos "uma exterioridade constitutiva, um fora dentro, uma dobra, em que o sujeito está inextricavelmente 'envolvido"' (ORLANDI, 2019, p.22, grifo da autora). A partir do funcionamento da ideologia e do inconsciente é que o equívoco escapa à apreensão do sujeito e o faz aceitar como natural um sonho nacionalista com aproximações ao fascismo, sob o argumento de que "O país precisa de todos os brasileiros" (PMDB, 2015). A promessa de um futuro a partir da reconstituição de um Estado moderno, próspero, democrático e justo requisita, por pressuposto, a eficácia da interpelação ideológica, produzindo um efeito de identificação do sujeito, materializado numa posição voluntária de compromisso com a sociedade [burguesa] e com o Estado [neoliberal]. 


\section{REVISTA DA ABRALIN}

\section{Considerações finais}

Nossa interpretação explicitou o efeito de identificação de interesses diversos, que, de forma simulada, apresentam-se, ou para resistência (confronto e negação) ou para a ratificação da ideologia dominante, a exemplo do que vem acontecendo com diversas políticas públicas no Brasil pós-golpe de 2016. Em termos mais precisos, a influência econômica na esfera política expõe o antagonismo de classes sociais no documento "Uma ponte para o Futuro".

A postura teórico-metodológica e política aqui assumida permitiu evidenciar que, pelos domínios de memória e de antecipação, as tentativas de reformulação dos sentidos de passado e futuro, metaforicamente representados pela ponte, estão intimamente entrelaçadas com a dinâmica das relações sociais, materializada no discurso neoliberal. Em seu efeito de evidência, tal discurso apaga significativamente a lógica do capital, valendo-se, por exemplo, do discurso religioso (pela esperança de um futuro próspero e pela intervenção divina simbolizada na figura de um Messias) e do discurso nacionalista para se sustentar, na sua relação constitutiva com o discurso econômico.

Por esta via, o documento "Uma ponte para o futuro" é apresentado como a única prescrição capaz de romper com o presente/passado, representado pelos governos petistas. Trata-se de um funcionamento discurso de viés econômico, utilizado no cenário político, unificando a um só golpe os interesses econômicos dominantes alinhados ao programa defendido pelo então PMDB, cujos desdobramentos foram levados a cabo pelo governo Temer (2016-2018), e continuam sendo, de modo ainda mais intenso, na atualidade.

Desse modo, a interpelação ideológica dominante buscou produzir no sujeito a identificação com um compromisso em defesa da nação, pelo funcionamento do discurso nacionalista, presente no imaginário nacional e acionado pelo domínio de memória. Ao mesmo tempo, a esperança atua no campo do desejo, antecipando para a atualidade uma imagem ideal de futuro, embora este nunca chegue, nunca aconteça. A construção da imagem dos inimigos na cena política nacional, materializada nas figuras de Lula e Dilma enforcados, é expressão de um processo discursivo próprio da referida cena, no qual amigos e inimigos são postos em polos distintos e, na arena política, os sentidos circulam para legitimar, no domínio de atualidade, os efeitos do processo histórico da luta de classes nas malhas do discurso.

A polaridade que daí é reforçada, bem como os retrocessos dos direitos arduamente conquistados pela classe trabalhadora são desdobramentos do que constitui a cena política brasileira atual, desenhando incertezas no futuro pelo qual, historicamente, o povo brasileiro tem sido obrigado a esperar. Para além da promessa [não cumprida] da salvação messiânica, tem restado mais a forca, para quem tenta cruzar o viaduto, do que o futuro para quem se identificou com o percurso apresentado na ponte. Todavia, como viaduto e ponte são construções sociais, é preciso recuperar a coragem e unir forças para desconstrui-los. Eis, portanto, o desafio histórico do tempo presente! 


\section{REVISTA DA ABRALIN}

\section{REFERÊNCIAS}

AMARAL, Maria Virgínia Borges. O avesso do discurso: análise de práticas discursivas no campo do trabalho. Maceió: EDUFAL, 2007.

BASTOS, Pedro Paulo Zahluth. A economia política do novo-desenvolvimentismo e do social desenvolvimentismo. Econ. soc. Campinas, v. 21, n. spe, p. 779-810, dec. 2012.

BASTOS, Pedro Paulo Zahluth. Ascensão e crise do governo Dilma Rousseff e o golpe de 2016: poder estrutural, contradição e ideologia. Rev. econ. contemp. Rio de Janeiro, v. 21, n. 2, p. 1-63, Aug. 2017.

BATISTA, Gisely Vieira. Neoliberalismo, crise do capital e banco mundial: bases e premissas das políticas sociais contemporâneas. In: CORREIA, Maria Valéria Costa; SANTOS, Viviane Medeiros dos (org.). Reforma sanitária da saúde: interesses do capital em curso. Maceió: Edufal, 2015.

BLYTH, Mark. Austeridade: a história de uma ideia perigosa. São Paulo:Autonomia Literária, 2017.

CÂNDIDO, Antônio. Prefácio. In: CHASIN, José. Integralismo de Plínio Salgado: formas de regressividade no capitalismo hiper-tardio. São Paulo: Livraria Editora Ciências Humanas Ltda, 1978.

CARVALHO, V. M. DE. Brasil, um país do futuro: projeções religiosas e leituras sobre um mote de Stefan Zweig. HORIZONTE - Revista de Estudos de Teologia e Ciências da Religião, v. 5, n. 9, p. 30-42, 3 dez. 2006.

CHASIN, José. Integralismo de Plínio Salgado: formas de regressividade no capitalismo hiper-tardio. São Paulo: Livraria Editora Ciências Humanas Ltda, 1978

CORTEN, André. Discurso e representação do político. In: INDURSKY, Freda; FERREIRA, Maria Cristina Leandro (org.). Os múltiplos territórios da Análise do Discurso. Porto Alegre: Sagra Luzzatto, 1999.

COURTINE, Jean-Jacques. Análise do discurso político: O discurso comunista endereçado aos cristãos. São Carlos: EdufSCar, 2014.

DUNKER, Christian Ingo Lenz. Mal-estar, sofrimento e sintoma: uma psicopatologia do Brasil entre muros. 1.ed.SãoPaulo:Boitempo, 2015.

DWECK, Esther; OLIVEIRA, Ana Luíza Matos de; ROSSI, Pedro (coord.). Austeridade e retrocesso: impactos sociais da política fiscal no Brasil. 1. ed. v. 1. São Paulo: Brasil debate e Fundação Friedrich Ebert, 2018.

ENGELS, Friedrich. Comentários sobre a contribuição à crítica da economia política, de Karl Marx. In: MARX, Karl. Contribuição à crítica da economia política. 2. ed. São Paulo: Expressão Popular, 2008.

FERNANDES, Florestan. As mudanças sociais no Brasil. In: IANNI, Octávio (org.). Florestan Fernandes: sociologia crítica e militante. 2. ed. São Paulo: Expressão Popular, 2011.

GUILBERT, Thierry. As evidências do discurso neoliberal na mídia. Campinas: Editora da Unicamp, 2020.

GUIMARÃES, Eduardo. Semântica do Acontecimento: um estudoenunciativo da designação. Campinas: Pontes Editores, 2017.

INDURSKY, Freda. Os (des)caminhos do discurso político brasileiro na contemporaneidade. In: GRIGOLETTO, Evandra; DE NARDI, Fabiele Stockmans (orgs.). Análise do discurso Discurso e sua história: avanços e perspectivas. Campinas: Pontes Editores, 2016. 


\section{REVISTA DA ABRALIN}

JINKINGS, Ivana. O despertar da montanha (prefácio). In: MÉSZAROS, István. A montanha que devemos conquistar: reflexões acerca do Estado. 1. ed. São Paulo: Boitempo, 2015.

KEYNES, Jonh M. O fim do "Laissez-faire" (1926). In: GUILBERT, Thierry. As evidências do discurso neoliberal na mídia. Campinas: Editora da Unicamp, 2020.

MARIANI, Bethania Sampaio Corrêa. Os primórdios da imprensa no Brasil (ou: de como o discurso jornalístico constrói a memória). In: ORLANDI, Eni Puccinelli (org.). Discurso fundador: a formação do país e a construção da identidade nacional. 2. ed. Campinas: Pontes, 2001.

MARX, Karl. Contribuição à crítica da economia política. São Paulo: Expressão Popular, 2008.

MARX, Karl; ENGELS, Friedrich. Manifesto comunista. 1. ed. revista. São Paulo: Boitempo, 2010.

MASCARO, Alysson Leandro. A crítica do Estado e do direito: a forma política e a forma jurídica. In: PAULO NETTO, José (org.). Curso livre Marx-Engels: a criação destruidora. 1. ed. São Paulo: Boitempo, Carta Maior, 2015.

MASSMANN, Patrícia Cristina Brasil. A constituição como discurso. 2019. 284 f. Tese (Doutorado em Direito) Universidade Presbiteriana Mackenzie, São Paulo, 2019.

NETTO, José Paulo; BRAZ, Marcelo. As crises e as contradições do capitalismo. In: PAULO NETTO, José; BRAZ, Marcelo. Economia política: uma introdução crítica. v.1. 8. ed. São Paulo: Cortez, 2012.

ORLANDI, Eni Puccinelli. Discurso e texto: Formulação e circulação dos sentidos. Campinas, SP: Pontes, 2001.

ORLANDI, Eni Puccinelli. Língua e nação: uma questão e seu quadro de referência teórico. Línguas e instrumentos linguísticos. Campinas, n. 23, v. 24, p.11-23, 2009.

ORLANDI, Eni Puccinelli. Análise do discurso. Princípios e procedimentos. 12. ed. Campinas, SP: Pontes Editores, 2015 .

ORLANDI, Eni Puccinelli. Eu, tu, ele. Discurso e real da história. 2. ed. Campinas, SP: Pontes Editores, 2017.

ORLANDI, Eni Puccinelli. Política do silêncio na América Latina. In: GRIGOLETTO, Evandra et al. (org.). Silêncio, memória, resistência: a política e o político no discurso. Campinas: Pontes Editores, 2019.

PARTIDO DO MOVIMENTO DEMOCRÁTICO BRASILEIRO. Uma ponte para o futuro. Brasília: Fundação Ulysses Guimarães, 2015.

PÊCHEUX, Michel. Papel da memória. In: ACHARD, Pierre et al. (org.). Papel da memória. Campinas, SP: Pontes Editores, 2007.

PÊCHEUX, Michel. Semântica e discurso: uma crítica à afirmação do óbvio. 5. ed. Campinas, SP: Ed. Unicamp, 2014.

PÊCHEUX, Michel. O discurso. Estrutura ou acontecimento. 7. ed. Campinas, SP: Ed. Unicamp, 2015.

RICOUER, Paul. A metáfora viva. São Paulo: Edições Loyola, 2000.

RIZZOTTO, Maria Lúcia Frizon. Capitalismo e saúde no Brasil nos anos 90: as propostas do Banco Mundial e o desmontado SUS. São Paulo: Hucitec, 2012.

ROBIN, Régine. História e linguística. São Paulo: Cultrix, 1973 


\section{REVISTA DA ABRALIN}

SUL21. Suástica, golpe militar, ameaças de morte contra Dilma: para mídia, manifestações pacíficas. Disponível em: <https://www.sul21.com.br/em-destaque/2015/03/suastica-golpe-militar-ameacas-de-morte-contradilma-para-midia-manifestacoes-pacificas/>. Acesso em: 27 set. 2019.

TEMER, Michel. [Carta enviada para Presidenta Dilma Rousseff]. Destinatário: Dilma Rousseff, 7 dez. 2015. Disponível em: http://g1.globo.com/politica/noticia/2015/12/leia-integra-da-carta-enviada-pelo-vice-micheltemer-dilma.html. Acesso em: 27 set. 2019.

ZOIDONARANJO, Florencio et al. Diccionario de geografía urbana, urbanismo y ordenación del território. 1. ed. Barcelona: Editorial Ariel, 2000. 